\title{
Carcinoma Erisipelóide
}

\author{
Carcinoma Erysipeloides
}

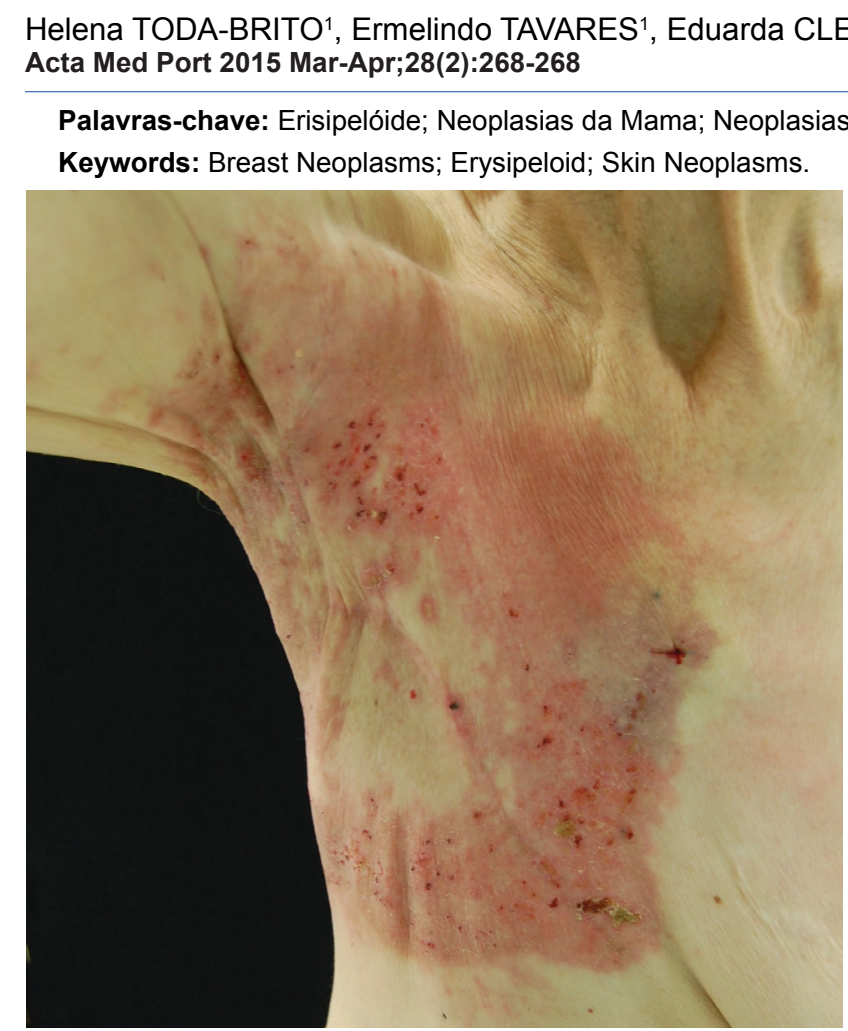

Figura 1 - Placa eritematosa, infiltrada, de limites bem definidos, medindo $28 \times 24 \mathrm{~cm}$, localizada nas faces anterior e lateral do hemitórax direito, com extensão para a região axilar ipsilateral

Mulher de 75 anos com adenocarcinoma da mama direita T4N3Mx, submetida a mastectomia radical, hormonoterapia e radioterapia. Um mês após terminar radioterapia desenvolveu placa eritematosa e pruriginosa nas faces anterior e lateral do hemitorax direito, medindo $28 \times 24 \mathrm{~cm}$. Os exames, histológico e imunohistoquímico (CK7+, Her2+, CK20-, RE-, RP-) revelaram metástase cutânea de adenocarcinoma da mama. A doente faleceu cinco meses após o início do quadro cutâneo, por infecção respiratória.

A metastização cutânea de uma neoplasia visceral

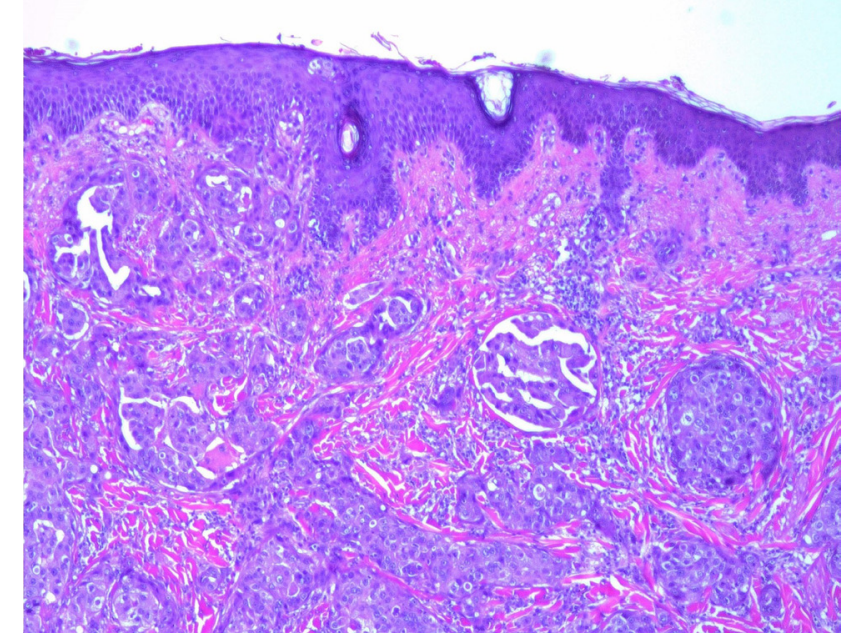

Figura 2 - Exame histológico de biópsia cutânea: infiltração dos vasos linfáticos da derme por células neoplásicas (hematoxilina-eosina, $40 \mathrm{x}$ )

é rara, ${ }^{1,2}$ associa-se mais frequentemente ao cancro da mama ${ }^{3} \mathrm{e}$ indica mau prognóstico. ${ }^{4} \mathrm{O}$ carcinoma erisipelóide constitui uma forma rara de metástase cutânea que decorre da obstrução dos vasos linfáticos da derme e tecido celular subcutâneo por células metastáticas. ${ }^{2,4,5}$ Clinicamente apresenta-se como placa eritematosa, infiltrada e bem delimitada que pode mimetizar radiodermite, erisipela e celulite. ${ }^{1,2,4,5} \mathrm{O}$ seu reconhecimento precoce é importante, podendo constituir a primeira manifestação da neoplasia ou da sua disseminação sistémica. ${ }^{5}$

\section{REFERÊNCIAS}

1. Nava G, Greer K, Patterson J, Lin KY. Metastatic cutaneous breast carcinoma: a case report and review of the literature. Can J Plast Surg. 2009;17:25-7.

2. Marcoval J, Gallego MI, Moreno A. Inflammatory cutaneous metastasis as a first sign of recurrence of squamous cell carcinoma of the lung. Actas Dermosifiliogr. 2008;99:157-9.

3. Salvado MC, Alberto MJ, Gonçalves LP, Proença R. Metástase palpebral reveladora de adenocarcinoma gástrico. Acta Med Port. 1998;11:87-90.

4. Lee JH, Won CY, Kim EK, Jung JH, Kim GM, Kim SY. Carcinoma erysipeloides from adenocarcinoma of the lung. Ann Dermatol. 2013;25:373-5.

5. Gugle A, Malpathak V, Zawar V, Deshmukh M, Kote R. Carcinoma erysipeloides: an unusual presentation mimicking radiation dermatitis. Dermatol Online J. 2008;14:26.

1. Serviço de Dermatologia e Venereologia. Hospital Distrital de Santarém. Santarém. Portugal.

2. Serviço de Anatomia Patológica. Hospital Distrital de Santarém. Santarém. Portugal.

Recebido: 15 de Novembro de 2013 - Aceite: 19 de Março de 2014 | Copyright $\odot$ Ordem dos Médicos 2015 


\section{Carcinoma Erisipelóide}

Acta Med Port 2015:28:268-268

Publicado pela Acta Médica Portuguesa, a Revista Científica da Ordem dos Médicos

Av. Almirante Gago Coutinho, 151

1749-084 Lisboa, Portugal.

Tel: +351218428215

E-mail: submissao@actamedicaportuguesa.com

www.actamedicaportuguesa.com

ISSN:0870-399X | e-ISSN: 1646-0758

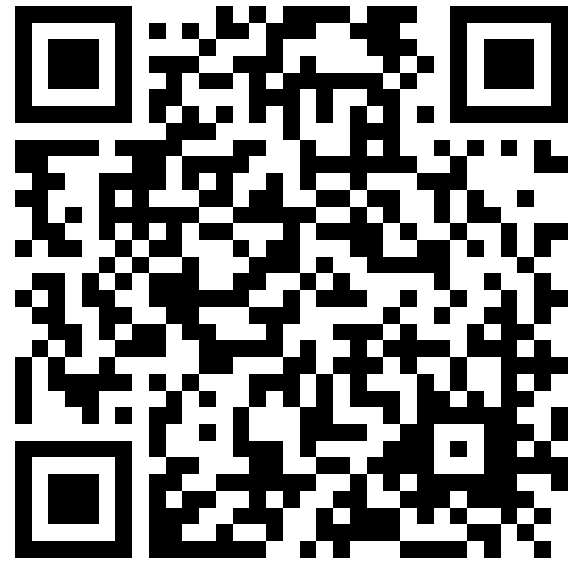

ACTA MÉDICA

PORTUGUESA 